\title{
Time to Rethink: A Reflection on the First Five Years of The Computer Games Journal and the Challenges Facing It
}

\author{
Malcolm Sutherland ${ }^{1}$
}

Published online: 3 November 2017

(C) Springer Science+Business Media, LLC 2017

On 11th May earlier this year, my co-editor-in-chief (Dr. John Sutherland) and I were listening to a broadcast of Jimmy Wales of Wikipedia being interviewed on BBC Radio 4. Near the end, when Jimmy was asked to reflect on the trials and tribulations of launching and running a technology company, he replied,

When you become an entrepreneur, even if you have a great idea, you have no idea where you are going. [sic.]

Almost exactly 5 years earlier, on 15th May 2012, Dr. Tony Maude, Dr. John Sutherland and I published online the first edition of what was then an independent academic journal for computer games students, lecturers, researchers and practitioners. Some of our editorial board members might remember this exciting event, not least those whose papers were published in that first edition of The Computer Games Journal (tCGJ).

Back then, tCGJ was but one of many TuDocs Ltd projects, and was envisioned as being a special asset of the company's main scheme, a digital technologies academy. Less than a month later, TuDocs Ltd-originally my own brainchild which began as a careers and e-portfolios website for computing students and prospective employers, but which had to be altered substantially as project after project died owing to lack of funding-was mothballed after our application for a major European business grant was rejected (an experience to which many games developers can relate).

In the midst of this final defeat and the setbacks leading up to it, we harboured grave concerns that this journal too would fail. Today, five and a half years later, the jury is still out. Every year, every edition has felt like the conquest of a game level: "What? I did it! I've reached the next level-how did that happen?" Every new

Malcolm Sutherland

malcolm@sutherlandpress.com

1 Glasgow, UK 
publication has been a small miracle, not least because it relied on the efforts, aspirations and cooperation of others. And it is other people-authors and reviewers, and more recently Springer personnel—who have kept this journal alive. To them I owe my sincere thanks and gratitude.

As the founders and editors of this journal, Tony, John and I respect and admire all those games developers, as well as games academics and research project leaders, who take risks and who fear that all their efforts could be in vain. This journal has survived, and it has thrived - thanks mainly to the voluntary efforts of our editorial board members-who have been writing and reviewing papers, and encouraging others to submit papers.

John and I (current editors-in-chief) also believe this journal has survived because from the beginning we have been bending the rules of academic publishing. When the TuDocs Ltd company was dissolved, we experienced that feeling of numbness and exposure to cold you get following a tooth extraction or some other deep wound. Not really knowing what else to do, we decided to take a risk and launch the first special edition featuring student dissertation chapters and essays: by the end of 2012, we had set a precedent. By the end of 2013, we had set another precedent: a special edition on games industry entrepreneurship, which included personal accounts by games developers and business specialists. By May 2014, we were processing submissions for a third student edition, and we also broke another convention by inviting experienced industry professionals and academics to submit short essays on what they felt was missing in the games industry-basically a collection of editorials. As ever, we could not have progressed this far and published these papers without the involvement of editorial board members.

However, by the end of 2013, many academics both in and outside the editorial board were clamouring for impact factor stats, and called for this journal to be integrated fully into online research citation databases, meta-data systems and search engines. In July 2013, Dr. Tony Maude and I attended an online publishing seminar, and we realised how inadequate our journal-hosting web tools were. For the first edition in 2014 (which was our sixth edition), I took a gamble in my editorial: in 1966 World Cup commentator style, I made the bold, premature declaration that we were taking this journal "to the next level" by finding a large corporate backer or buyer which would make the journal more professional (everyone here in the UK is familiar with the voice of Kenneth Wolstenholme who, seeing some England fans storming the pitch, remarked, "They think it's all over," and then suddenly sighted Geoff Hurst approaching the West Germany goalkeeper and blurted, "It is now!") At the time of writing, we were still lost in the woods. We approached a couple of web data dissemination companies; we even proposed passing this journal onto a university. A few weeks later, a miracle happened: two representatives from Springer and Apress contacted us and proposed to buy out the journal...AND employ us as editors-in-chief to run tCGJ as a Springer title.

So began the second phase in tCGJ's history.

tCGJ's migration from our simple, humble Weebly.com-based independent platform to Springer's corporate, centralised one was not without some trepidation and, as expected, it did ruffle feathers. Some editorial board members prior to the journal sale expressed discontentment and left. The journal's front ('home') page 
was altered in terms of layout and appearance. Interestingly, in late 2014 this migration coincided with the REF' 14 academic assessment-a sort-of Stalinesque purge in which academics' jobs are judged by how many papers per year they've managed to output - and so we received a flurry of submissions whilst Santa's (ahem, Springer's) little helpers were scurrying in the background, figuring out how to transfer and enhance the contents of this journal.

In April 2015, the first papers for this journal appeared on Springer's website; around a year later, we closed down the old Weebly site and shifted the guideline documents; and a year further on still, the pre-Springer papers were migrated onto the existing journal site. To date, we have published over 30 papers under Springer's banner. In 2015 and 2016, this journal has featured standard research papers, plus a few editorials and book reviews. However, this year, our Apress/Springer line managers (Welmoed Spahr and Natalie Pao) agreed to allow us to bend the rules once again: we have published some more students' dissertation-based papers, and we are bringing back special editions (we know from our 6 years' experience that many games and other computing students are engaged in exciting, cutting-edge research).

This journal is now hosted on a professional academic publications database with all the accompanying SEO and metrics, which academics expect in the publish-orperish game (which, fundamentally, has not changed in half a century ever since The New Yorker published Mischa Richter's distressing cartoon, "It's Publish or Perish", of a disgraced academic standing blindfolded in front of a firing squad). Yet its course is still perilous and uncertain. During the summer months of 2017 we have witnessed a noticeable drought: almost no decent papers were received during July, August or September. During this time, we have escalated our promotion of the journal mainly through social media; but so far our efforts have yielded nothing more than the occasional 'like'.

Therefore the journal is facing another challenge. Like the voluminous, cold stone Edwardian barn of a house that my co-editor has just sold, in recent months I have detected damp, a 'mustiness', on the journal front. A diminished level of enthusiasm and communication among many members of the editorial board. Fewer prospective authors sending in decent papers. This trend seems to have appeared just in the last few months.

I can only speculate on its causes. It is a bad officer who blames his men-so I will not attempt to dish out blame amongst any editorial board members, prospective authors, or Springer colleagues. Perhaps I have not been promoting this journal widely or vigorously enough using modern, attractive marketing tools and hooks, which many gamers, games students and researchers now expect. Or perhaps it is simply that we do not employ writers and cannot provide prospective authors any monetary inducement (however, many other Springer titles attract thousands of prospective authors per annum, and most academics rely on remuneration from within their own departments, so this claim is only plausible). Maybe it is tCGJ's impact factor that, understandably, is not as high as many prospective authors might desire since this journal has only recently been acquired. A fourth uncomfortable possibility is that in 2014, both John and I departed from academia; there is a widely held belief that once one is outside the ivory tower, the 
door is closed and barred forever, but this too sounds like a 'cop-out excuse'; in short, we no longer enjoy direct face-to-face communication with active games students and other researchers. Or perhaps our social media-based (Facebook, LinkedIn and Twitter) efforts to promote this journal are being drowned out by all the "noise" of the hundreds of memes, hooks, bandwagoning and other messages pouring into these feeds every day. Perhaps a sixth significant reason is that the games industry, especially its tools, ideas and innovations, is shrouded in secrecy, and people on the cutting-edge neither have the time for nor are prepared to disclose their magicians' secrets.

As do professionals in academic research, games teaching, games development and marketing, we need to convert this journal from being a fledging title sailing on a journey of serendipity (receiving fascinating papers and student dissertations every now and then) into a more solid production line with regular input and output, governed by guidelines, deadlines and targets. It is impossible to run a business if you remain only a hobbyist. And I would like to remind the naysayers who complain about Springer's paywall, yes there is an Open Access option, and many authors have made their articles on this journal free to view as a result.

On a more critical note, let me also mention that, especially in recent months, too many prospective authors (whose papers editorial board members and I have rejected) cannot write intelligible sentences, apparently never "read the manual", or do not appreciate video games for what they are. It amazes me how many people out there labour under the illusion that the art of writing an article is about piling as much academic gibberish as possible onto every subject, verb and object, thus obscuring what might be a new idea or invention. Too often, a prospective author has sent me a two-column, badly structured manuscript in a read-only file and has apparently made no effort to read the guidelines for authors. Then there are the numerous authors who think that making five students test out another 'serious' game and saying they like it using the dreaded Likert Scale ("Yes, I liked the professor's game-can I pass this module now?") qualifies as research. I could rant on and on about other bugbears, but I have said more than enough.

May I make a suggestion? Here are two golden rules for making a video game. Rule No. 1: a game is supposed to be FUN. In the same way as food is supposed to taste nice. If it's not amusing, it's not a game. Even though the processes of researching and designing, and writing about, games entail dreary toil and due diligence, the product must stand apart from all the gloomy sameness. Rule No. 2: the outcome of a game is supposed to be unpredictable; there should be a large element of chance and uncertainly.

Just as with plagiarism, it is important for scholars to avoid repetition. For example, the problem with many (not all) 'serious' games, I fear, is that by predetermining the outcome (i.e. a game that teaches you to become a bricklayer) the element of surprise is thus dissolved like an alkali metal in water. Game-based violence, although morally relevant, is not the only sheriff in town either. After a quarter-century, my co-editor-in-chief is still waiting for that ultimate article on games violence in which it is proved beyond all reasonable doubt that certain violent actions in video games lead directly to a real-life person committing a violent crime, and with a careful prescription on how governments can halt such a 
chain reaction (one caveat I will venture to make is that it is also not necessary for a game to be violent in order to be entertaining; and holding that view does not make you 'a girl').

I say this to everyone who wants to write something about video games, both in this journal or elsewhere: do not be blinded by monotony. Use it; do not let it use you. Don't just write games and communicate about them to satisfy the pen-pushers and earn a pay cheque; deal with the pen-pushers and use your pay cheques so you to write games and communicate about them. Do not let your passion for video game ideas, characters, design or markets be snuffed out. Forgive me for quoting something religious, but as St Paul exhorted the Galatians, "I am surprised that you have turned away from that which you had received with joy... Oh, you fools-who has deceived you?"

The time has come again to rethink. This is how this journal has survived and will continue to do so. My co-editors and I have had to rethink on many previous occasions as we proposed and released different kinds of editions, and when we sought out an organisation to take over the journal and make it more professional. Already we are re-thinking ways to promote this journal. However, it is you-the authors, editorial board members and readers - who can make or break it.

So let me close off by leaving you with my grand vision: imagine that in 5 years time tCGJ is the most popular, highest-ranked interactive media-themed title in Springer's tree. Whatever paper of yours that is published here is read by thousands of people overnight and cited by hundreds of other authors. You publish a series of papers in tCGJ, and professors and research directors around the world see your name again and again. And they start sending you invitations. More research opportunities, new projects, and bigger grants. And maybe, just maybe, in the process you stumble across something that could transform the games industry and startle gamers. And other authors submitting papers to this journal are doing the same, and you can't wait to read about what they're doing. 